\title{
Effective Mitigation of Voltage Flicker in Power System using 12-Pulse Converter based Statcom
}

\author{
J.H.V.Veera Raghava \\ Lecturer \\ R.V.R \& J.C College of Engg, \\ Chandramoulipuram, Chowdavaram, Guntur- \\ 522019, Andhra Pradesh.
}

\begin{abstract}
A Power quality problem is an occurrence manifested as a nonstandard voltage, current or frequency that results in a failure of end user equipments. Voltage flicker is considered as one of the most severe power quality problems caused by large time-varying loads like arc furnaces. To reduce this kind of disturbances, Static Var Compensators (SVC) has been used so far which have a limited flicker mitigation capability. In the paper, 12-pulse converter based STATCOM has been proposed for effective mitigation of Voltage flicker and reduction of total harmonic distortion in the system. All the simulations have been performed using MATLAB Software. The obtained results show that 12-pulse converter based STATCOM is very efficient and effective for the mitigation of voltage flickering and THD reduction.
\end{abstract}

\section{Keywords}

Power Quality; Voltage Flicker; Static Synchronous Compensator (STATCOM).

\section{INTRODUCTION}

The increased concern for power quality has resulted in measuring power quality variations, studying the characteristics of power disturbances and providing solutions to the power quality problems. In Power system, the power quality problem causes reduction of power supplied to the customers from its nominal value. Utilities often focus on disturbances like flicker, harmonics etc [2]. from end-user equipment which are the main power quality problems.

Flicker is understood to be the sensation that is experienced by humans when subjected to huge changes in the voltage. Large industrial loads, such as electric arc furnaces [4-14] cause voltage distortion like harmonics and voltage fluctuation in the feeding AC system. The arc furnace is a non-linear load which is the main generator of voltage flicker, behaves in the form of a constant reactance and a variable resistance [11]. Voltage flicker mitigation depends on reactive power control. To limit the effects of these disturbing loads, compensation devices which are nothing but FACTS devices have usually to be connected for the compensation of the reactive power fluctuations which causes this voltage flickering [11].

\author{
K.Chandra Sekhar, PhD \\ Professor \& Head of EEE \\ R.V.R \& J.C College of Engg, \\ Chandramoulipuram, Chowdavaram, Guntur- \\ 522019, Andhra Pradesh.
}

Among all the FACTS devices, Static VAR Compensator (SVC) such as Thyristor Switched Capacitor TSC, Thyristor Controlled Reactor (TCR), and FCTCR are the most frequently used devices for reduction of voltage flickering, but they have problems such as injecting a large amount of harmonics.

Beyond these, STATCOM (Shunt Structure) which is SVC device provides effective voltage flicker mitigation in power system which has the higher potential to be exceptionally reliable for voltage flickering and in reducing the THD [11].

The concept of instantaneous reactive power components is used in the controlling system which is nothing but 'dqo'components.

A 6-Pulse converter based STATCOM [6] was used to mitigate the voltage flicker. With respect to the harmonic problem, a novel 12-pulse converter based STATCOM was designed to minimize the load harmonics and mitigate the propagation of voltage flicker in to the system. The obtained results clearly confirmed the efficiency of the 12-Pulse converter based STATCOM is more and it gives effective voltage flicker mitigation and THD reduction.

\section{CONFIGURATION FOR VOLTAGE FLICKER MITIGATION}

Voltage oscillation was produced by a 3-phase flicker source. The Studied power system[1] with complete STATCOM control and flicker source scheme is shown in figure 1. A STATCOM is used to regulate voltage on a $69 \mathrm{KV}$ transmission Network. A $440 \mathrm{~V}$ load connected to a bus B1 through a $69 \mathrm{KV} / 440 \mathrm{~V}$ transformer represents a plant absorbing continuously charging currents similar to an arc furnace, thus producing voltage flicker. The STATCOM regulates the bus B3 voltage through the leakage reactance of the 3-phase two winding transformers by generating a secondary voltage with the primary voltage which is a flicker source of $69 \mathrm{KV}$. 


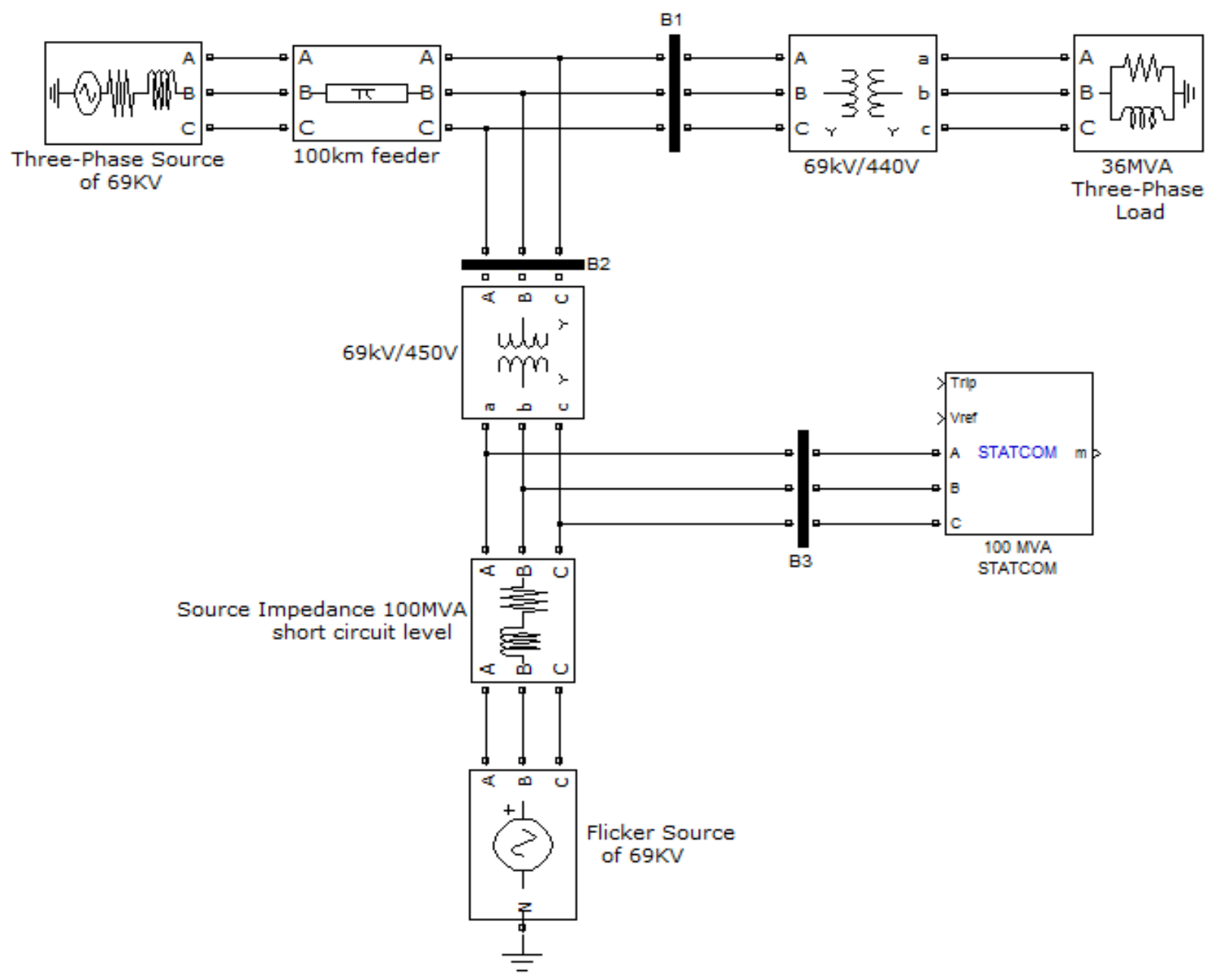

Fig 1: The Studied Power System

\section{CONTROLLING SYSTEM}

The concept of instantaneous reactive power is used for the controlling system. Following is, the 3-Phase voltage has been transformed to the synchronous reference frame [7] (Park or dqo transformation). This transformation leads to the appearances of three instantaneous space vectors: $V_{d}$ on the $d-$ axis (real or direct axis), $\mathrm{V}_{\mathrm{q}}$ on the q-axis (imaginary or quadature axis) and $\mathrm{V}_{\mathrm{o}}$, from the 3-phase voltage of $\mathrm{V}_{\mathrm{a}}, \mathrm{V}_{\mathrm{b}}$ and $V_{c}$. The related equations of this transformation are:-

$$
\begin{aligned}
& \mathrm{V}_{\mathrm{d}}=\frac{2}{3}\left(V_{a} \sin (w t)+V_{b} \sin (w t-120)+V_{c} \sin (w t+120)\right) \\
& \mathrm{V}_{\mathrm{q}}=\frac{2}{3}\left(V_{a} \sin (w t)+V_{b} \sin (w t-120)+V_{c} \sin (w t+120)\right)
\end{aligned}
$$

$$
\mathrm{V}_{\mathrm{o}}=\frac{1}{3}\left(V_{a}+V_{b}+V_{c}\right)
$$

A dynamic computation shows that the voltage oscillations in the connecting node of the flicker generating load to the network are created by three vectors: real current $\left(i_{p}\right)$, imaginary current $\left(\mathrm{i}_{q}\right)$, and the derivative of the real current with respect to time $\left(\frac{d\left(i_{p}\right)}{d t}\right)$.
In general, for the complete voltage flicker compensation, the compensating current $\left(\mathrm{i}_{\mathrm{c}}\right)$ regarding the currents converted the dqo axis is given a

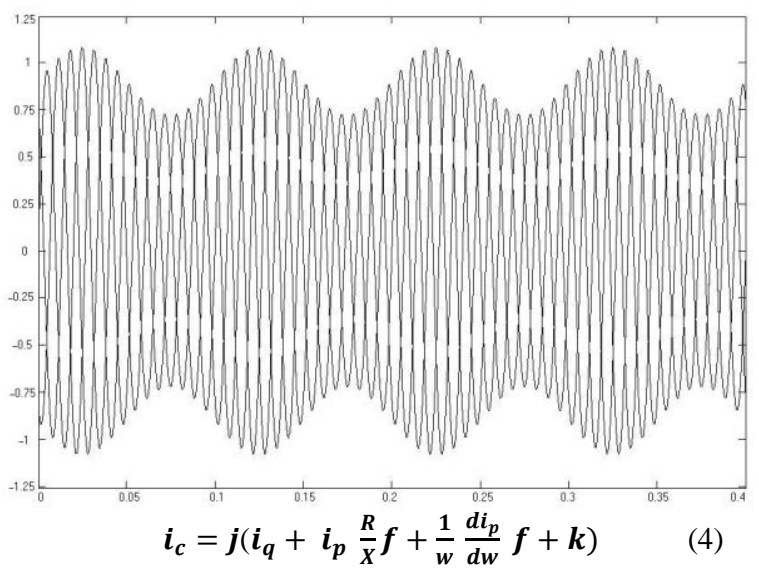

Fig 2: The generated voltage flicker by the flicker source 
Where $\mathrm{R}$ and $\mathrm{X}$ are the synchronous resistance and reactance of the line and $f$ is the correcting coefficient. The constant $k$ is also used to eliminate the reactive power of the network [3]. If the compensation current of the above equation is injected to the network, the whole voltage flicker will be eliminated. Regarding the equation, related to dqo transformation of the 3 -phase voltages to the instantaneous vectors, it is obvious that $\mathrm{V}_{\mathrm{d}}$ and $\mathrm{V}_{\mathrm{o}}$ vectors are close to zero values and $\mathrm{V}_{\mathrm{q}}$ is a component among three vectors which is responsible for voltage oscillation of the network. This analysis of the 3phase voltage flicker is presented in this paper. The voltage flicker exerted by the voltage source to the circuit is shown in figure 2. The instantaneous components of the 3-phase voltage flicker waveform are also shown in figure 3 .

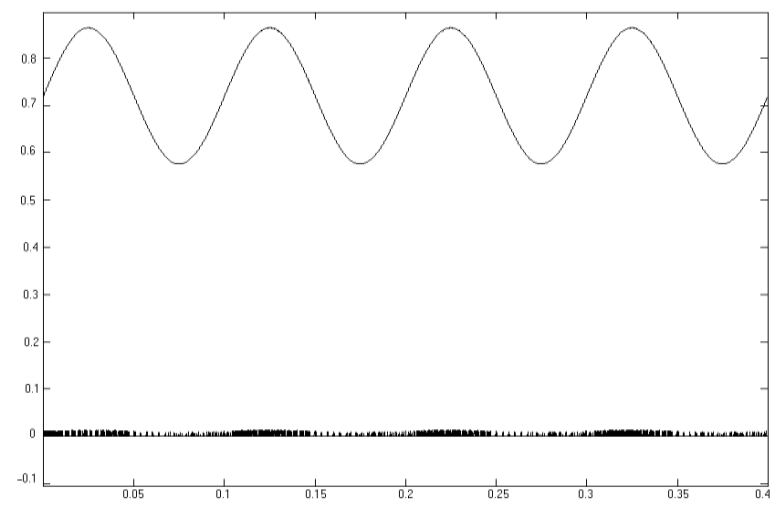

Figure 3. The instantaneous components of the 3-phase voltage flicker waveform.

So, we may conclude that the decrease of the voltage flicker of the network is based on the amount of the imaginary component of the instantaneous voltage $\left(\mathrm{V}_{\mathrm{q}}\right)$.

\section{SIMULATION AND ANALYSIS OF THE RESULTS}

First, using a 3-phase converter to dqo, the instantaneous vectors $\mathrm{V}_{\mathrm{d}}, \mathrm{V}_{\mathrm{q}}$ and $\mathrm{V}_{\mathrm{o}}$, are evaluated from the output 3-phase voltages whose equations were explained in the previous section. Since the controlling system uses just $\mathrm{V}_{\mathrm{q}}$ to control the STATCOM, a de-multiplexer is used to extract $\mathrm{V}_{\mathrm{q}}$ voltage from dqo voltage vectors. The obtained $\mathrm{V}_{\mathrm{q}}$ is then entered as an input to the controlling function upon the MATLAB software. The controlling function generates the amount of conducting angle, needed for the GTO's of the STATCOM. A phase shifting block is designed to control the appropriate phase angle of the exerting pulses upon the GTO's of the STATCOM. The outputs of this unit are entered in to the STATCOM as inputs.

In order to investigate the influence of the STATCOM as an effective mitigating device for voltage flicker, three levels of compensation are simulated in MATLAB. First, the voltage flickering is created by a 3-phase voltage flicker source and is simulated without STATCOM. Then a 6-pulse voltage source converter based STATCOM is used and finally for a complete voltage flicker mitigation a 12-pulse voltage-source converter based STATCOM is designed. The mitigation and their results are presented in this section.

4.1. Voltage flicker generation and Measurement under without STATCOM

In this stage, voltage disturbance is generated in power system by using 3-phase voltage flicker source. This voltage flickering is measured, and is simulated and analyzed under without STATCOM by using MATLAB. In this, we will observe the distortions in the output waveform which have been exerted in to the system, and get reduced in the further levels or stages. The generated voltage flicker by the flicker source is shown in figure 2 .

\subsection{Mitigation using 6-pulse converter based STATCOM}

Six valves compose the converter and each valve is made up of a GTO with a diode connected in anti-parallel. In this type of STATCOM, each GTO is fired and blocked one time per line voltage cycle. In this case, each GTO in a single branch is conducted during a half-cycle (180 degrees) of the fundamental period. The combined pulses of each leg have a 120 degrees phase difference to produce a balanced set of voltages. By adjusting the conducting angle of the GTO's, the generated voltage and then the injected or absorbed power of the STATCOM are controlled. In this respect, the mitigated output voltage by 6-pulse voltage-source converter STATCOM is presented in the figure 4.

It can be seen that the mitigation effects of this compensator is very effective in mitigating the voltage flicker, but the output voltage waveform has some considerable harmonics shown in figure 5 .

The instantaneous output line-to-line voltage $\left(\mathrm{V}_{\mathrm{ab}}\right)$ of the 6-pulse voltage-source converter is as follows:

$$
V_{a b}=\sum_{n=1,3,5, \ldots}^{\infty} \frac{4 V s}{n \Pi} \cos \frac{n \Pi}{6} \sin n\left(w t+\frac{\Pi}{6}\right)
$$

As we see it is clear from the above equation that, the even harmonics in the instantaneous line-to-line voltage component are 5, 7, and 11, 12 and higher. The harmonic spectrum of the compensated output voltage by 6-pulse voltage source converter STATCOM is shown in figure 6 . It can be observed from the harmonic spectrum that $5^{\text {th }}$ and $7^{\text {th }}$ harmonics have considerable level comparing to the fundamental harmonics. At this stage, THD will be about $12-15 \%$ which can be reduced in the coming stage (i.e.) 12-pulse voltage-source $\begin{array}{ll}\text { converter } & \text { based }\end{array}$

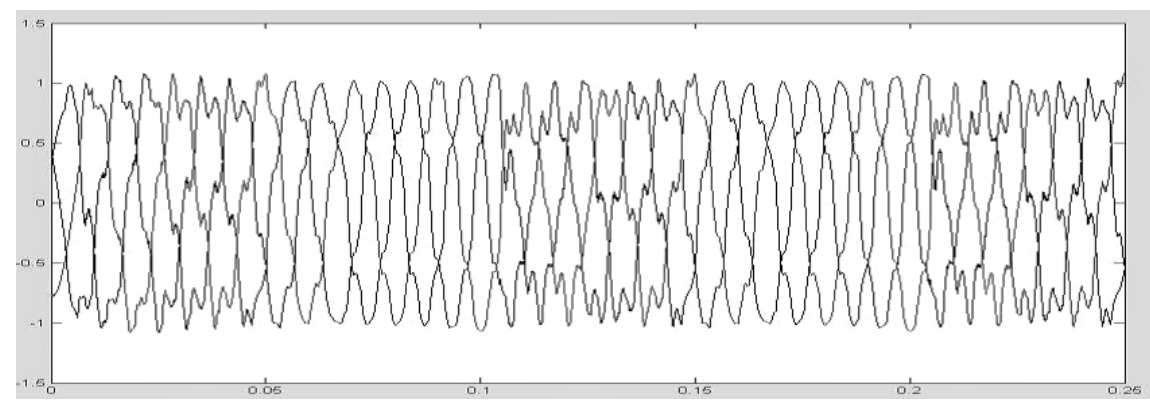

Fig 4: Mitigated output voltage of 6-pulse Converter based STATCOM 


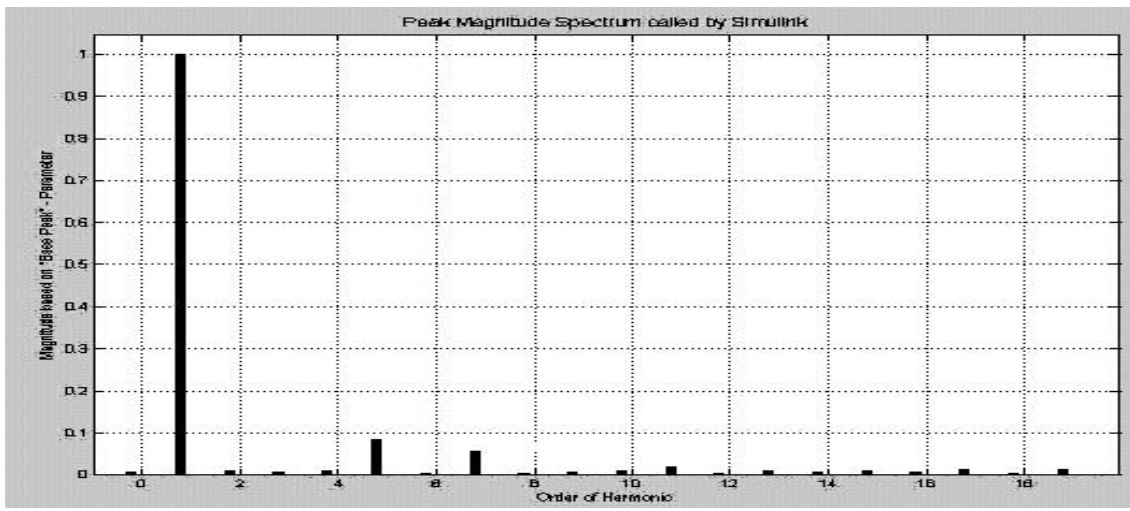

Fig 5: The harmonic Spectrum of the mitigated output voltage of a 6-pulse converter based STATCOM.

4.3. Mitigation and Reduction of THD using 12-pulse converter based STATCOM

In order to reduce the harmonic contents at the output voltage, the number of pulses can be increased, forming a multi-pulse configuration. Multi-pulse converters are composed by $n(n=2,4,8 \ldots \ldots)$, where $n$ is the number of pulses. 6-pulse bridges connected in parallel on the same DC bus and interconnected in series through transformers on the AC side. Depending on the number of pulses, these transformers and their connections can become very complex. Two 6-pulse bridges are connected, forming a 12-pulse converter for a complete voltage flicker mitigation design. In this case, the first converter is connected with a wye-wye transformer and the second one with a wye-star transformer. These are linked together using a three winding transformer. wye-star transformer. These are linked together using a three winding transformer. Moreover, the delta connected secondary of the second transformer must have $\sqrt{3}$ times the turns compared to the wye-connected secondary and the pulse train to one converter is shifted by 30 degrees with respect to the other.

The complete STATCOM control system scheme is implemented on the power system introduced in figure 1 .

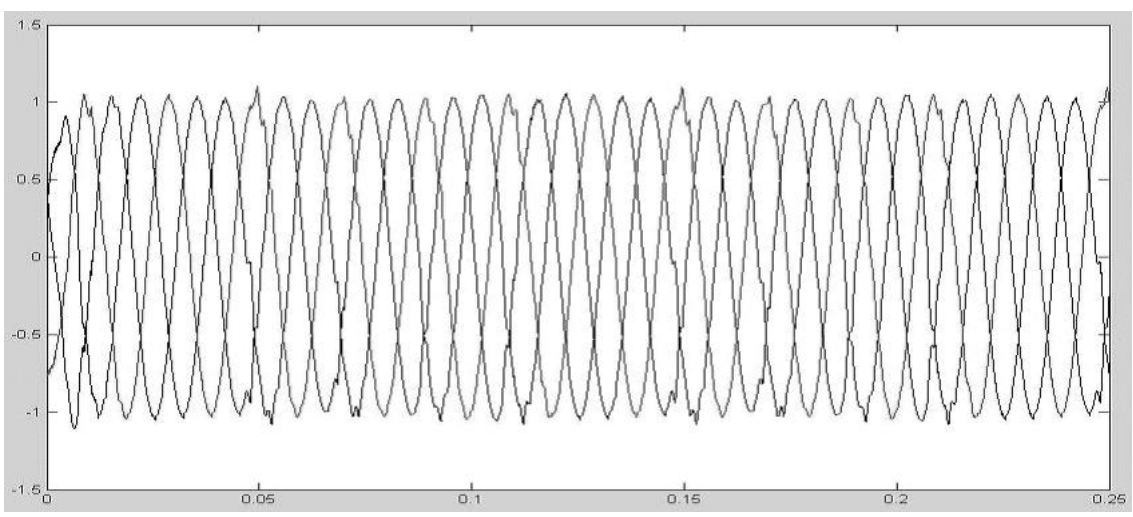

Fig 6: The mitigated output voltage of 12-pulse converter Based STATCOM

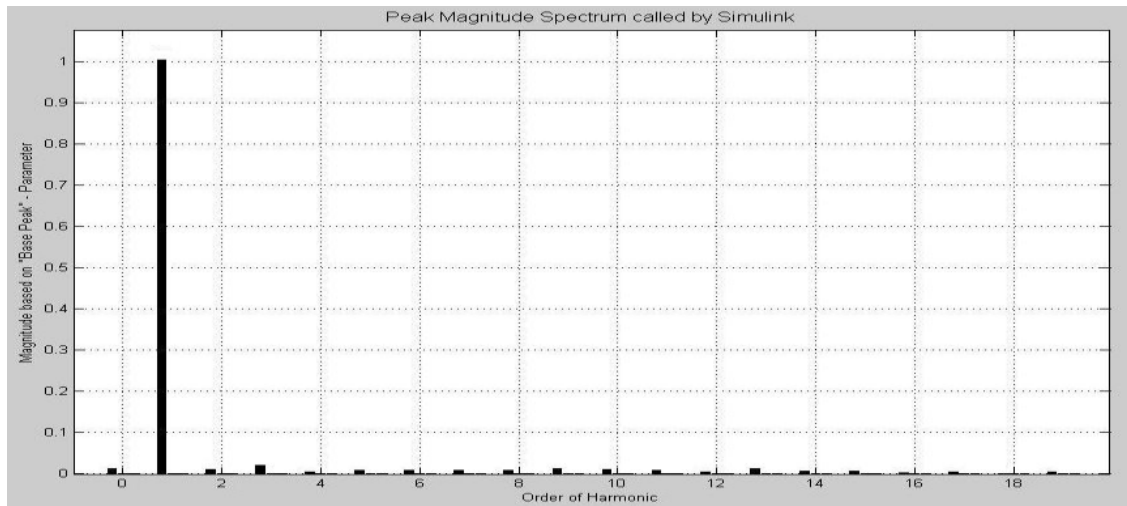

Fig 7: The harmonic Spectrum of the mitigated output voltage of a 12-pulse converter based STATCOM. 
The mitigated output voltage by 12-pulse voltage-source converter based STATCOM and its harmonic spectrum are represented in figures 6 and 7 respectively. In this voltage flicker is almost removed from the output voltage and a sinusoidal waveform is obtained. Similarly all the harmonics are almost removed (i.e.) the THD will be around $2.5 \%$ only.

\section{CONCLUSION}

The design and application of STATCOM technology based on voltage-source converters for voltage flicker mitigation is discussed in this paper. Generation and Mitigation is done in three stages. First voltage flicker is generated by 3-phase voltage flicker source and the results are measured under without STATCOM, then a 6-pulse converter based STATCOM and finally a 12-pulse converter based SATCOM are designed for complete voltage flicker mitigation without harmonics.

All the simulated results which have been performed in MATLAB show that a 6-pulse converter based STATCOM is efficiently effective in reducing the voltage flicker of the generating loads. However, there is injection of the harmonics from STATCOM into the system which can be reduced with the increase of the pulse number from 6 to 12 as 12-pulse converter based STATCOM. The obtained results clearly demonstrate that 12-pulse converter based STATCOM can reduce the voltage flicker and reduce the total harmonic distortion caused by nonlinear loads.

\section{ACKNOWLEDGMENTS}

I wish to express my deep sense of gratitude to my Supervisor (Dr.K.Chandra Sekhar) for his generous guidance, patience and support during this submission of Research paper.

\section{REFERENCES}

[1] Akagi, H.; Kanazawa, Y.; Nabae, A. (1984): Instantaneous Reactive Power Compensator Comprising Switching Devices Without Energy Storage Components, IEEE Trans. on Industry Applications, No.3, Vol.20, pp. 625630. No.3, Vol.20, pp. 625-630.

[2] AliZa'fari, (2011): Mitigation of Flicker using STATCOM with Three-Level 12-pulse Voltage Source Inverter, World Academy of Science Engineering and Technology, Vol.73, pp.263-268.

[3] Chen, C.S.; Chuang, H.J.; Hsu, C.T.; Tscng, S.M. (2001): Stochastic Voltage Flicker Analysis and Its Mitigation for Steel Industrial Power Systems, IEEE Power Tech Proceedings, Vol.1.
[4] Clouston, J.R.; Gurney, J.H.(1999): Field Demonstration of Distribution Static Compensator Used to Mitigate Voltage Flicker, IEEE Power Engineering Society Winter Meeting, Vol.2, pp. 1138- 1141.

[5] Collantes-Bellido, R.; Gomez, T. (1997): Identification and Modeling of a Three Phase Arc Furnace for Voltage Distribution Simulation, IEEE Trans. on Power Delivery; Vol.12, No.4, (1997), pp. 1812-1817.

[6] Czarkowski, D.; Sun, J.; Zabar, Z. (2002): Voltage Flicker Mitigation Using PWM-Based Distribution STATCOM, IEEE Power Engineering Society Summer Meeting, Vol.1, pp. 616-621.

[7] El-khattam, W.; Elnady, A.; Salama, M.A. (2002): Mitigation of AC Arc Furnace Voltage Flicker Using the Unified Power Quality Conditioner, IEEE Power Engineering Society Winter Meeting, Vol.2, pp. 735 739.

[8] Enslin, J.H.R. (1998): Unified Approach to Power Quality Mitigation, International Symposium on Industrial Electronics (ISIE '98), IEEE Proceedings, Vol.1, pp. 820.

[9] Fahmi, N.R.; Norris, W.T.; Zhang, Z. (2001): Flicker Analysis and Methods for Electric Arc Furnace Flicker (EAF) Mitigation (A Survey), IEEE Power Tech Proceedings, Vol.1.

[10] Hara, Y.; Masada, E.; Miyatake, M.; Shutoh, K. (2000): Application of Unified Flow Controller for Improvement of Power Quality IEEE Power Engineering Society Winter Meeting, Vol.4, pp. 2600-2606.

[11] Kolluri, S.; McGranaghan, M.F.; Tang, L. (1997): Voltage Flicker Prediction for Two Simultaneously Operated AC Arc Furnaces,IEEE Trans. on Power Delivery; Vol.12, No.2, pp. 985-991.

[12] Larsson, T.; Poumarede, C. (1999): STATCOM, an efficient means for flicker mitigation, IEEE Power Engineering Society Winter Meeting, Vol.2, (Jan-4Feb 1999), pp. 1208-1213.

[13]Levillain,C.; Lombard,X.; Poumarede,C.; Saadate,S.; Zouiti,M.(1998): Electronic Based Equipment for Flicker Mitigation, Proceedings of International Conference on Harmonics And Quality of Power, Vol.2, pp. 1182-1187.

[14] Mckim, J. (1997): The UIE Flicker-meter Demystified, Hewlett-Packard's Power Products Division. 